www.uoc.edu/idp

ACTUALIDAD NORMATIVA

\title{
Novedades legislativas
}

\author{
Jordi Garcia Albero
}

Profesor de los Estudios de Derecho y Ciencia Política (UOC)

Fecha de publicación: octubre de 2020

\section{Boletín Oficial del Estado (BOE)}

Real Decreto-ley 8/2020, de 17 de marzo, de medidas urgentes extraordinarias para hacer frente al impacto económico y social del COVID-19.

BOE núm. 73, 18 de marzo de 2020.

https://www.boe.es/boe/dias/2020/03/18/pdfs/BOE-A-2020-3824.pdf

Real Decreto-ley 11/2020, de 31 de marzo, por el que se adoptan medidas urgentes complementarias en el ámbito social y económico para hacer frente al COVID-19.

BOE núm. 91, 1 de abril de 2020.

https://www.boe.es/boe/dias/2020/04/01/pdfs/BOE-A-2020-4208.pdf

Resolución de 15 de abril de 2020, de la Dirección General de la Agencia Estatal de Administración Tributaria, por la que se modifica la de 11 de marzo de 2020, sobre asistencia a los obligados tributarios y ciudadanos en su identificación telemática ante las entidades colaboradoras, con ocasión del pago de deudas con tarjetas de crédito y de débito, mediante el sistema de firma no avanzada con clave de acceso en un registro previo (sistema CI@VE PIN).

BOE núm. 111, 21 de abril de 2020.

https://www.boe.es/boe/dias/2020/04/21/pdfs/BOE-A-2020-4538.pdf

Real Decreto-ley 15/2020, de 21 de abril, de medidas urgentes complementarias para apoyar la economía y el empleo.

BOE núm. 112, 22 de abril de 2020.

https://www.boe.es/boe/dias/2020/04/22/pdfs/BOE-A-2020-4554.pdf 
Real Decreto-ley 16/2020, de 28 de abril, de medidas procesales y organizativas para hacer frente al COVID-19 en el ámbito de la Administración de Justicia.

BOE núm. 119, 29 de abril de 2020.

https://www.boe.es/boe/dias/2020/04/29/pdfs/BOE-A-2020-4705.pdf

Resolución de 29 de abril de 2020, de la Secretaría General de Administración Digital, por la que se acuerda la continuación de los procedimientos administrativos de autorización de nuevos sistemas de identificación y firma electrónica mediante clave concertada y cualquier otro sistema que las Administraciones consideren válido a que se refieren los artículos 9.2 c) y 10.2 c) de la Ley 39/2015, de 1 de octubre, del Procedimiento Administrativo Común de las Administraciones Públicas, en aplicación de la disposición adicional tercera del Real Decreto 463/2020, de 14 de marzo, por el que se declara el estado de alarma para la gestión de la situación de crisis sanitaria ocasionada por el COVID-19. BOE núm. 120, 30 de abril de 2020.

https://www.boe.es/boe/dias/2020/04/30/pdfs/BOE-A-2020-4733.pdf

Instrucción de 22 de junio de 2020, de la Dirección General de Seguridad Jurídica y Fe Pública (Ministerio de Justicia), sobre la remisión telemática al Registro de Bienes Muebles de contratos privados de financiación suscritos mediante un sistema de identificación y prestación del consentimiento basado en firmas no criptográficas.

BOE núm. 184, 4 de julio de 2020.

https://www.boe.es/boe/dias/2020/07/04/pdfs/BOE-A-2020-7296.pdf

Resolución de 15 de julio de 2020, de la Dirección General de la Agencia Estatal de Administración Tributaria, por la que se modifica la de 19 de marzo de 2020, por la que se establecen las condiciones para la tramitación y contestación en la Sede Electrónica de la Agencia Estatal de Administración Tributaria de los requerimientos de información a que se refiere el artículo 97.5 del Reglamento General de Recaudación, aprobado por Real Decreto 939/2005, de 29 de julio, dirigidos a entidades de crédito y referidos a bienes inmuebles.

BOE núm. 201, 24 de julio de 2020.

https://www.boe.es/boe/dias/2020/07/24/pdfs/BOE-A-2020-8520.pdf

\section{Diario Oficial de la Unión Europea (DOUE) Legislación, comunicaciones e informaciones comunitarias}

Reglamento interno de Eurojust relativo al tratamiento y a la protección de datos personales. DOUE L 50, 24 de febrero de 2020.

https://eur-lex.europa.eu/legal-content/ES/TXT/PDF/?uri=CELEX:32020Q0224(02)\&from=ES

Reglamento (UE) 2020/261 del Consejo de 19 de diciembre de 2019 por el que se modifica el Reglamento (UE) 389/2012 sobre cooperación administrativa en el ámbito de los impuestos especiales por lo que se refiere al contenido de los registros electrónicos (ST/14108/2019/INIT).

DOUE L 58, 27 de febrero de 2020.

https://eur-lex.europa.eu/legal-content/ES/TXT/PDF/?uri=CELEX:32020R0261\&from=ES 
Reglamento (UE) 2020/283 del Consejo de 18 de febrero de 2020 por el que se modifica el Reglamento (UE) $904 / 2010$ en lo que respecta a las medidas para reforzar la cooperación administrativa a fin de combatir el fraude en el ámbito del IVA (ST/14128/2019/INIT).

DOUE L 62, 2 de marzo de 2020.

https://eur-lex.europa.eu/legal-content/ES/TXT/PDF/?uri=CELEX:32020R0283\&from=ES

Directiva (UE) 2020/284 del Consejo de 18 de febrero de 2020 por la que se modifica la Directiva 2006/112/CE en lo que respecta a la introducción de determinados requisitos para los proveedores de servicios de pago (ST/14127/2019/INIT).

DOUE L 62, 2 de marzo de 2020.

https://eur-lex.europa.eu/legal-content/ES/TXT/PDF/?uri=CELEX:32020L0284\&from=ES

Dictamen del Comité Europeo de las Regiones-Trabajo en plataformas digitales: retos normativos en las esferas local y regional.

DOUE C 79, 10 de marzo de 2020.

https://eur-lex.europa.eu/legal-content/ES/TXT/PDF/?uri=CELEX:52019IR2655\&from=ES

Decisión del Consejo de Administración del Centro Europeo para la Prevención y el Control de las Enfermedades de 9 de septiembre de 2019 relativa a las normas internas sobre las limitaciones de determinados derechos de los interesados en relación con el tratamiento de datos personales en el marco del funcionamiento del Centro Europeo para la Prevención y el Control de las Enfermedades. DOUE L 98, 31 de marzo de 2020.

https://eur-lex.europa.eu/legal-content/ES/TXT/PDF/?uri=CELEX:32020Q0331(01)\&from=ES

Recomendación (UE) 2020/518 de la Comisión de 8 de abril de 2020 relativa a un conjunto de instrumentos comunes de la Unión para la utilización de la tecnología y los datos a fin de combatir y superar la crisis de la COVID-19, en particular por lo que respecta a las aplicaciones móviles y a la utilización de datos de movilidad anonimizados (C/2020/3300).

DOUE L 114, 14 de abril 2020.

https://eur-lex.europa.eu/legal-content/ES/TXT/PDF/?uri=CELEX:32020H0518\&from=ES

Comunicación de la Comisión orientaciones sobre las aplicaciones móviles de apoyo a la lucha contra la pandemia de covid-19 en lo referente a la protección de datos (C/2020/2523).

DOUE C 124 I, 17 de abril de 2020.

https://eur-lex.europa.eu/legal-content/ES/TXT/PDF/?uri=CELEX:52020XC0417(08)\&from=ES

Conclusiones del Consejo sobre la configuración del futuro digital de Europa (ST/8711/2020/INIT). DOUE C 202 I, 16 de junio de 2020.

https://eur-lex.europa.eu/legal-content/ES/TXT/PDF/?uri=CELEX:52020XG0616(01)\&from=ES

Decisión (UE) 2020/969 de la Comisión de 3 de julio de 2020 por el que se establecen disposiciones de aplicación relativas al responsable de la protección de datos, a las restricciones de los derechos de los interesados y a la aplicación del Reglamento (UE) 2018/1725 del Parlamento Europeo y del Consejo, y por la que se deroga la Decisión 2008/597/CE de la Comisión (C/2020/4183).

DOUE L 213, 6 de julio de 2020.

https://eur-lex.europa.eu/legal-content/ES/TXT/PDF/?uri=CELEX:32020D0969\&from=ES 
Reglamento de Ejecución (UE) 2020/1030 de la Comisión de 15 de julio de 2020 por el que se establecen las especificaciones técnicas de los requisitos de datos aplicables al tema uuso de las TIC y comercio electrónico» para el año de referencia 2021, de conformidad con el Reglamento (UE) 2019/2152 del Parlamento Europeo y del Consejo (Texto pertinente a efectos del EEE) (C/2020/4700). DOUE L 227, 16 de julio de 2020.

https://eur-lex.europa.eu/legal-content/ES/TXT/PDF/?uri=CELEX:32020R1030\&from=ES

Comunicación de la Comisión sobre la protección de la información confidencial por los órganos jurisdiccionales nacionales en los procedimientos de aplicación privada del Derecho de la competencia de la UE (C/2020/4829).

DOUE C 242, 22 de julio de 2020.

https://eur-lex.europa.eu/legal-content/ES/TXT/PDF/?uri=CELEX:52020XC0722(01)\&from=ES

Reglamento de Ejecución (UE) 2020/1121 de la Comisión de 29 de julio de 2020 relativo a la recogida y el intercambio de estadísticas y observaciones de los usuarios sobre los servicios de la pasarela digital única de conformidad con el Reglamento (UE) 2018/1724 del Parlamento Europeo y del Consejo (Texto pertinente a efectos del EEE) (C/2020/5075).

DOUE L 245, 30 de julio de 2020.

https://eur-lex.europa.eu/legal-content/ES/TXT/PDF/?uri=CELEX:32020R1121\&from=ES

Decisión 2020-04 del Colegio de Comisarios de 15 de julio de 2020 relativa a las normas internas sobre las limitaciones de determinados derechos de los titulares de datos en relación con el tratamiento de datos personales en el marco de las actividades llevadas a cabo por Eurojust.

DOUE L 287, 2 de septiembre de 2020.

https://eur-lex.europa.eu/legal-content/ES/TXT/PDF/?uri=CELEX:32020Q0902(01)\&from=ES

Jordi Garcia Albero

Profesor de los Estudios de Derecho y Ciencia Política (UOC)

〈https://dx.doi.org/10.7238/idp.v0i31.3263〉

Universitat

Oberta de Catalunya 